\title{
Low cement content SCC (Eco-SCC) - the alternative for ready-mix traditional concrete
}

\author{
Maciej Urban ${ }^{1, *}$ \\ ${ }^{1}$ Cracow University of Technology, 24 Warszawska St. PL-31-155 Cracow, Poland
}

\begin{abstract}
Self-Compacting Concrete (SCC) is often regarded for in-situ applications as a more expensive and less environmentally friendly version of traditional concrete for use in places where the latter is highly inconvenient for various reasons. To counteract this belief, a new type of SCC has been proposed, called Eco-SCC or green-SCC. In comparison to typical SCC this building material has lower powder content resulting in low cement content and a slightly lower paste volume. The disadvantage of this approach is high water content and low viscosity resulting in high vulnerability of fresh concrete to sedimentation. Additionally, comparing to EN-206 limits, mixes with too low cement content are often obtained. This is why a research program has been undertaken to check the possibility of obtaining fresh Eco-SCCs of higher viscosity, thereby fulfilling all EN-206 requirements. It was possible to obtain concretes of $\mathrm{C} 25 / 30-\mathrm{C} 35 / 45, \mathrm{SF} 2$, VF2, PL2, containing $265-300 \mathrm{~kg} / \mathrm{m}^{3}$ of cement and $165-190 \mathrm{~kg} / \mathrm{m}^{3}$ of water owing to the use of limestone powder and typical rounded aggregate of local origin with very low sand to a total aggregate ratio of $s / a=0.4$. Based on Global Warming Potential (GWP) analysis, a modification of Eco-SCC definition is proposed: Eco-SCC is an SCC having cementitious materials volumetric content no greater than $100 \mathrm{dm}^{3} / \mathrm{m}^{3}$ (or mass content no greater than $315 \mathrm{~kg} / \mathrm{m}^{3}$ ).
\end{abstract}

\section{Introduction}

The building industry often treats Self-Compacting Concrete (SCC) as a more expensive and less environmentally friendly alternative to traditional concrete for places where the use of traditional concrete is, for a variety reasons, highly questionable (e.g. complicated formwork, very dense reinforcement, limited access etc.) [1]. To overcome this belief, a new type of SCC has been proposed, called Eco-SCC or green-SCC $[2,3]$. According to the definition proposed by Wallevik [1,4], this material should contain a maximum $315 \mathrm{~kg} / \mathrm{m}^{2}$ of binder. Binder here is defined as the sum of particles lower than $1 / 8 \mathrm{~mm}$, excluding aggregate particles. In many respects this is a doubtful assumption. Firstly, the paste volume needed to obtain the self-compactibility limit is correlated to the loose voids volume in the aggregate skeleton [5]. This means that such a kind of concrete has to contain high water doses resulting in low viscosity and low segregation-resistance. An example of this problem is shown in [2]. It was possible to obtain only SF1, VF1 consistence classes and C16/20-C25/30 strength

\footnotetext{
* Corresponding author: maurban@pk.edu.pl
} 
classes (acc. to EN-206) using c.a. $200 \mathrm{~kg} / \mathrm{m}^{3}$ of water, resulting in $w / c>0.75$ so were too high for use in practice (nominally with exception for X0 exposure class). Then, balancing 'on the edge' with durability requirements is the second important drawback of this approach. Thirdly, judging from the point of view of water and superplasticizer demand, the author in [5] has shown that aggregate fumes act in the same way as other additions. Thus, there is no reason to distinguish between these materials and treat them differently, especially as even inert additions, due to their densifying effect, play a significant role in enhancing both mechanical and durability properties of SCC [6-8]. Fourthly, according to common practice (see e.g. $[9,10]$ ), SF1, VS1 SCCs have a very limited usability. Lastly, according to ERMCO contemporary data [11], more than $50 \%$ of ready mix concrete production is within the range C25/30-C30/37 with a tendency to rise. The market share of lower strength classes (and so $\mathrm{X} 0$ exposure class) is lower than $20 \%$ with a tendency to regress. Additionally, the mean value of cementitious materials' equivalent content is within the range $290-320 \mathrm{~kg} / \mathrm{m}^{3}$. For comparison, typical exposure classes in the $\mathrm{C} 25 / 30-\mathrm{C} 30 / 37$ strength range require at least 280 to $300 \mathrm{~kg} / \mathrm{m}^{3}$ of cement equivalent, maintaining a maximum $w / c$ limit in the range 0.55 - 0.65. This means that these ranges have to be used as the target for Eco-SCC design, assuming that this kind of concrete should be used more often than accidentally (as, according to [11], SCC shares c.a. 3-4\% of the ready-mix concrete market). This is why the Eco-SCC limit should be altered so as not to exceed $315 \mathrm{~kg} / \mathrm{m}^{3}$ of cement equivalent materials, treating all inert additions (as defined in EN 430-1) as a part of aggregate. Minimizing the content of inert additions is also important, but only from the point of view of lowering the overall cost of concrete, as its environmental cost (see Table 1) is low.

This is why in the following part of the article this target range is used to check the possibility of Eco-SCC design in practice, additionally assuming that at least a VS2 bottom consistence limit and VF2 viscosity are to be obtained. These two last requirements were chosen to widen the resulting Eco-SCC applicability.

\section{Materials}

Considering the aforementioned target values, a binary binder made of cement and an inert addition was chosen. This is why a commercial limestone powder (lp) dedicated for the use in SCC was selected. According to [1] the lowest values for carbon footprint are typically reached for cements containing ground granulated blast-furnace slag, therefore commercial cement of CEM II/B-S 32.5R type was selected. Its mean strength value measured according to EN 196-1 was 47.5 MPa. To fluidize the mixes, commercial superplasticizer (sp) of polycarboxylate type was used (density: $1.07 \mathrm{~kg} / \mathrm{dm}^{3}$ ).

Aggregate was composed of river material obtained from the same local quarry. It consisted of mid-sand and sorted rounded coarse aggregate (Carpathian flysch). All granular compositions used are shown in fig. 1.

\section{Design method}

SCC compositions were designed according to the original method shown in [5], and then modified for the purpose of this research. Aggregate composition was designed following the original procedure (to obtain minimum voids in a loose state). Additionally, PL2 passing ability class (i.e. L-box, 3 bars) was assumed. To assess this feature, Van and Montgomery criterion [12] was used. The target value was $V_{a}=660-670 \mathrm{dm}^{3} / \mathrm{m}^{3}$. The final composition is shown in Fig. 1. The sand to total aggregate ratio $(s / a)$ of this composition is only $40 \%$ (compare to e.g. [2,13], where much higher values were used). 


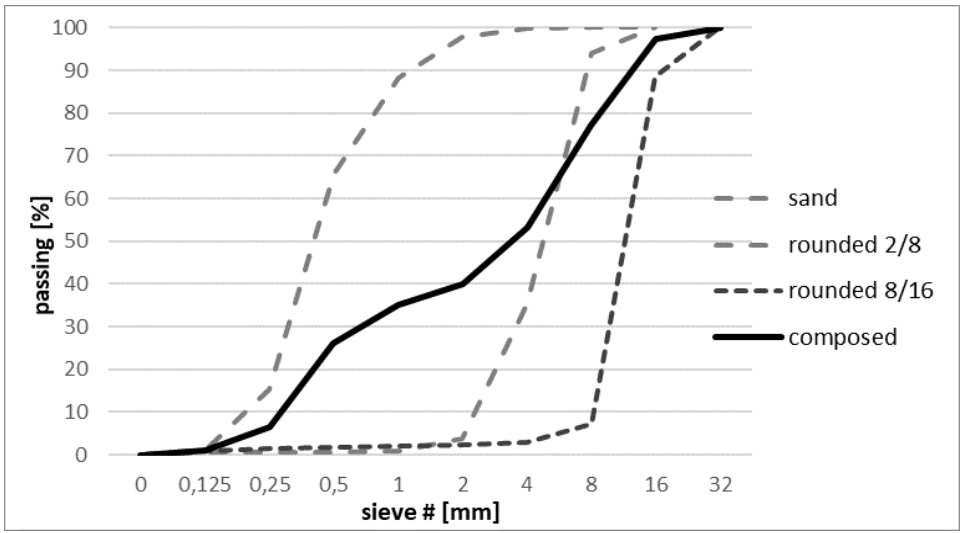

Fig. 1. Aggregate sieve size distribution.

Paste compositions were prepared assuming a $w / c$ ratio on $0.5,0.55,0.6,0.65$ and 0.70 levels. To obtain higher viscosity (preferably VF2) water-to-binder ratio $(w / b)$ was set in the range $0.33-0.41$. This range was chosen to secure water content not higher than $185 \mathrm{~kg} / \mathrm{m}^{3}$, following typical Japanese recommendations [7]. Next, superplasticizer dose was optimized using the following procedure. Firstly, plain cement paste containing a maximum allowable dosage of superplasticizer ( $2.0 \%$ of binder mass $b$ ) was prepared and tested using standard Haegermann cone with rising $w / c$ up to sedimentation limit $D_{\text {sed }}$ (following the original procedure). Fluidity of this plain paste was treated afterwards as the target for testing paste with addition. Next, paste compositions with binder proportions fulfilling the aforementioned criteria were calculated. Then, following the original procedure, $w / b$ ratio correction due to aggregate fumes ( $a_{f}=2.5 \%$ of aggregate mass, measured by washing acc. to EN 933-1) was calculated assuming paste content (i.e. the sum of $V_{w}+V_{c}+V_{l p}$ ) equal to $330 \mathrm{dm}^{3}$ per $1 \mathrm{~m}^{3}$ of concrete. Final paste composition for testing was calculated by the equation (1)

$$
\frac{w}{w+l p+a_{f}}=\frac{w_{c o r r}}{c+l p}
$$

The paste (containing $w_{\text {corr }}, c$ and $l p$ ) was tested with steeply rising $s p$ dose to reach $D_{\text {sed }}$. Established this way $s p$ content was treated as the final one for fresh concrete composition design, treating aggregate water demand as anti-sedimentation reserve for the paste.

Additionally, based on the same aggregate composition, five mixes treated as the reference ones were designed. Two of them were standard concretes ( $\mathrm{S} 2$ consistence) with $w / c=0.5, c=345 \mathrm{~kg} / \mathrm{m}^{3}$ and $w / c=0.7, c=268 \mathrm{~kg} / \mathrm{m}^{3}$ (denoted in Tables 1-3 as 50S and 70S, accordingly). They were prepared for strength comparison with compliant SCC using the same cement content. Another three mixes were chosen to represent typical binder-rich SCC based on paste of the highest obtainable viscosity. The design procedure strictly followed the one shown in [5]. Maximum viscosity was obtained using $l p / c=0.33$ and $s p=1.8 \% b$. This composition was used as the bottom extreme, denoted 33R. Next, following the same procedure and $l p / c$ ratio, $w / b$ ratios for $s p=1.2$ and $0.6 \% b$ were found. These mixes were denoted 40R and 55R, accordingly.

\section{Testing}

Dry aggregate mixture was prepared in a counter-current mixer. Ready-mixed paste was prepared in a bucket using a mechanical hand mixer. Superplasticizer was added premixed with water without delay. The mixing time was c.a. 75 s. Concrete mixes were obtained by 
adding the paste (immediately after preparation) to dry aggregate mix in an amount enabling the assumed consistence level to be obtained. The mixing time was c.a. $2 \mathrm{~min}$. Then, fresh concrete was tested using slump flow, V-funnel and L-box PL2 tests. If the consistence was too viscous, the batch was remixed with additional paste portion, and the tests were repeated. Both compositions are shown in Table 1. In two cases, for $w / c=0.65$ and 0.70 (denoted 65-2, $70-3$ and 70-4, accordingly), the mixes were redesigned: the first one because the passing ability was too low for the given cement content, and the second one because the paste and $s p$ contents were too high. Lastly, 15 cubes of $100 \mathrm{~mm}$ rib were formed for compressive strength testing. Strength was evaluated after 1 day ( 3 samples), 28 days ( 6 samples) and 90 days (6 samples).

Table 1. Mix compositions.

\begin{tabular}{|c||c|c|c|c|c|c|c|c|c|c|}
\hline Mix no. & $\mathbf{c} *$ & $\mathbf{w} *$ & $\mathbf{l p} *$ & $\mathbf{s p} *$ & $\mathbf{a} *$ & $\mathbf{V}_{\mathbf{b}} * *$ & $\mathbf{V}_{\text {paste }} *$ & $\mathbf{V}_{\mathbf{c}} * *$ & $\mathbf{w} / \mathbf{c}$ & $\mathbf{w / b}$ \\
\hline \hline $33 \mathrm{R}$ & 503 & 165 & 165 & 12 & 1,542 & 223 & 388 & 162 & 0.33 & 0.25 \\
\hline $40 \mathrm{R}$ & 454 & 175 & 149 & 7.3 & 1,581 & 201.5 & 376.5 & 146.5 & 0.385 & 0.29 \\
\hline $50 \mathrm{~S}$ & 345 & 173 & 0 & 1.75 & 1,835 & 113 & 286 & 113 & 0.5 & 0.5 \\
\hline $50-1$ & 336 & 167 & 168 & 6.5 & 1,689 & 170.5 & 337.5 & 108.5 & 0.5 & 0.33 \\
\hline $50-2$ & 345 & 172 & 171 & 8 & 1,664 & 174.5 & 346.5 & 111.5 & 0.5 & 0.33 \\
\hline $55 \mathrm{R}$ & 369 & 200 & 122 & 3 & 1,628 & 164 & 364 & 119 & 0.55 & 0.41 \\
\hline $55-1$ & 314 & 174 & 190 & 5 & 1,671 & 171.5 & 345.5 & 101.5 & 0.55 & 0.34 \\
\hline $55-2$ & 314 & 174 & 190 & 5.8 & 1,671 & 171.5 & 345.5 & 101.5 & 0.55 & 0.34 \\
\hline $60-1$ & 290 & 174 & 173 & 3.5 & 1,710 & 157.5 & 331.5 & 93.5 & 0.6 & 0.375 \\
\hline $60-2$ & 302 & 182 & 182 & 3.6 & 1,674 & 164.5 & 346.5 & 97.5 & 0.6 & 0.375 \\
\hline $65-1$ & 278 & 182 & 165 & 2.6 & 1,710 & 150.5 & 332.5 & 89.5 & 0.65 & 0.41 \\
\hline $65-2$ & 278 & 181 & 176 & 3.4 & 1,703 & 154.5 & 335.5 & 89.5 & 0.65 & 0.37 \\
\hline $70-1$ & 256 & 177 & 209 & 4.2 & 1,698 & 159.5 & 336.5 & 82.5 & 0.69 & 0.38 \\
\hline $70-2$ & 268 & 187 & 220 & 4.4 & 1,651 & 167.5 & 354.5 & 86.5 & 0.69 & 0.38 \\
\hline $70-3$ & 253 & 176 & 187 & 3.3 & 1,724 & 150.5 & 326.5 & 81.5 & 0.7 & 0.40 \\
\hline $70-4$ & 268 & 187 & 198 & 3.5 & 1,674 & 159.5 & 346.5 & 86.5 & 0.7 & 0.4 \\
\hline $70 \mathrm{~S}$ & 268 & 188 & 0 & 0.7 & 1,866 & 87 & 276 & 87 & 0.7 & 0.7 \\
\hline \hline GWP **** & 0.55 & 0.00034 & 0.032 & 0.72 & 0.00345 & - & - & - & - & - \\
\hline
\end{tabular}

* Units: $\left[\mathrm{kg} / \mathrm{m}^{3}\right]$

** Units: $\left[\mathrm{dm}^{3} / \mathrm{m}^{3}\right]$

*** Units: $[\mathrm{kg} \mathrm{CO} / \mathrm{kg}]$

\section{Analysis}

All results are shown in Tables 2-3. The strength results obtained on the same $w / c$ ratio for SCCs and traditional concretes were between $\pm 4 \%$ range for all testing times, so that the difference was negligible. This means that in this particular case limestone powder was inert, without the dilution effect reported e.g. in $[8,14]$, and might be treated as a part of aggregate.

PL2 passing ability class was obtained in the range of $335-350 \mathrm{dm}^{3} / \mathrm{m}^{3}$ of paste, so that Van and Montgomery formula (see [12]) predicted this feature with reasonable accuracy. 
GWP (Global Warming Potential, in $\mathrm{kg} \mathrm{CO}_{2}$ per $1 \mathrm{~m}^{3}$ of concrete) values in Table 2 were calculated using data shown in Table 1 (taken from [1]). Additionally, a hypothetical substitution of used cement by CEMI or CEMIII/B by simple 1:1 method was assumed. The adequate GWP values are shown in the last two columns of Table 2. Next, correlations between this parameter and other material characteristics were checked. Only two significant relationships of GWP were found: with $w / c$ ratio, see Fig. 2, and with cement content, see Fig. 3. For comparison, see also Fig. 4. This means that cement content is an absolutely dominating factor in terms of GWP assessment for SCC containing rounded aggregate and inert addition(s).

The Eco-concrete limit proposed in $[1,4]$ is $125 \mathrm{kgCO}_{2} / \mathrm{m}^{3}$. The results shown in Table 2 and fig. 3 reveal that cement type (strictly: the level of Portland clinker replacement by lowGWP active addition) dominates all other aforementioned factors: only concrete compositions recalculated assuming CEM III/B usage fulfilled this condition (up to over 350 $\mathrm{kg} / \mathrm{m}^{3}$ content, thereby far exceeding the top limit of eco-concrete requirement given in the Introduction). The results for CEM II/B-S are c.a. $75 \%$ higher. In the case of CEM I the difference is c.a. $260 \%$. For comparison: rising cement content from 250 to $450 \mathrm{~kg} / \mathrm{m}^{3}$ (mixes $70-3$ and 40R, accordingly) resulted in c.a. 70\% GWP increase (Fig. 3); rising of $w / c$ ratio by c.a. 0.2 resulted in 26\% GWP rise for Eco-SCC and 38\% for binder-rich SCC (Fig. 2).

Table 2. Test results - Global Warming Potential (GWP) $\left[\mathrm{kg} \mathrm{CO}_{2} / \mathrm{m}^{3}\right]$ and consistence.

\begin{tabular}{|c||c|c|c|c|c||c|c|}
\hline Mix no. & GWP & $\mathbf{D}_{\mathbf{0}}$ [cm] & $\mathbf{t}_{\mathbf{5 0 0}}[\mathbf{s}]$ & $\mathbf{t}_{\mathbf{v}}[\mathbf{s}]$ & $\mathbf{L}-\mathbf{b o x}$ PL2 & $\begin{array}{c}\text { GWP** } \\
(\mathbf{C E M I I I / B )}\end{array}$ & $\begin{array}{c}\text { GWP** } \\
(\mathbf{C E M I})\end{array}$ \\
\hline $33 \mathrm{R}$ & 296 & 82 & 6.5 & 20.8 & $100 \%$ & 171 & 433 \\
\hline $40 \mathrm{R}$ & 265 & 76 & 7 & 15.4 & $100 \%$ & 152 & 388 \\
\hline $50 \mathrm{~S}$ & 200 & $6^{*}$ & - & - & - & 113 & 295 \\
\hline $50-1$ & 201 & 70 & 7.5 & 34 & $60 \%$ & 116 & 291 \\
\hline $50-2$ & 207 & 74 & 4.5 & 13 & $84 \%$ & 120 & 299 \\
\hline $55 \mathrm{R}$ & 215 & 71 & 3 & 6 & $91 \%$ & 122 & 314 \\
\hline $55-1$ & 188 & 70 & 7 & 25 & $78 \%$ & 110 & 275 \\
\hline $55-2$ & 189 & 70 & 8 & 18 & $85 \%$ & 111 & 275 \\
\hline $60-1$ & 174 & 68 & 5.5 & 16.6 & $70 \%$ & 101 & 253 \\
\hline $60-2$ & 180 & 72 & 2.8 & 11 & $89 \%$ & 105 & 264 \\
\hline $65-1$ & 166 & 66 & 3.5 & 15.1 & $52 \%$ & 97 & 242 \\
\hline $65-2$ & 167 & 67 & 5 & 14.8 & $89 \%$ & 99 & 244 \\
\hline $70-1$ & 156 & 65 & 7.5 & 33 & $80 \%$ & 93 & 226 \\
\hline $70-2$ & 163 & 74 & 2.6 & 12 & $87 \%$ & 97 & 237 \\
\hline $70-3$ & 154 & 63 & 8 & 46 & $44 \%$ & 91 & 223 \\
\hline $70-4$ & 162 & 68 & 3.3 & 12 & $87 \%$ & 96 & 236 \\
\hline $70 S$ & 155 & $5 *$ & - & - & - & 88 & 228 \\
\hline \hline
\end{tabular}

* slump

** calculated assuming hypothetic substitution of used cement by CEMI $(\mathrm{GWP}=0.82)$ and CEMIII/B $(\mathrm{GWP}=0.3)$ 


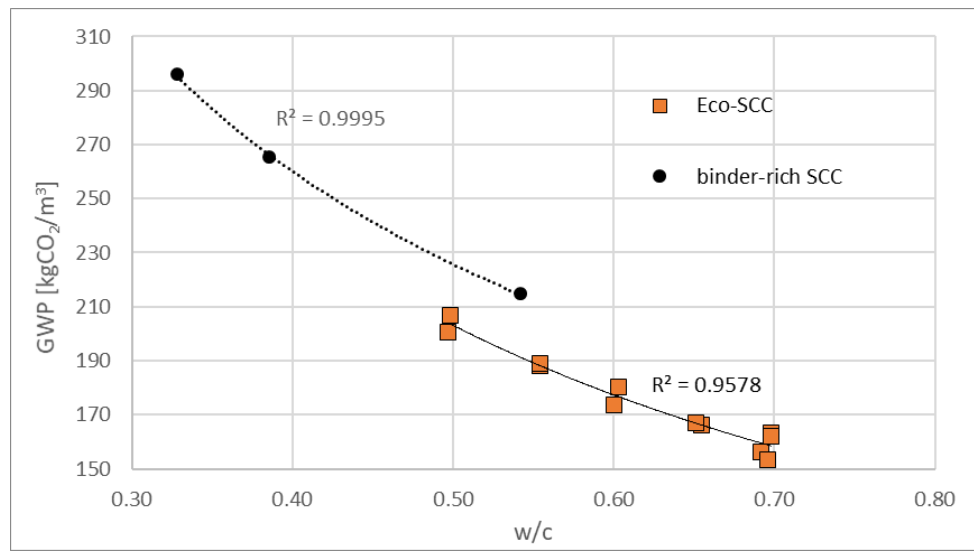

Fig. 2. Global Warming Potential (GWP) as a function of $w / c$ for binder-rich and Eco-SCC.

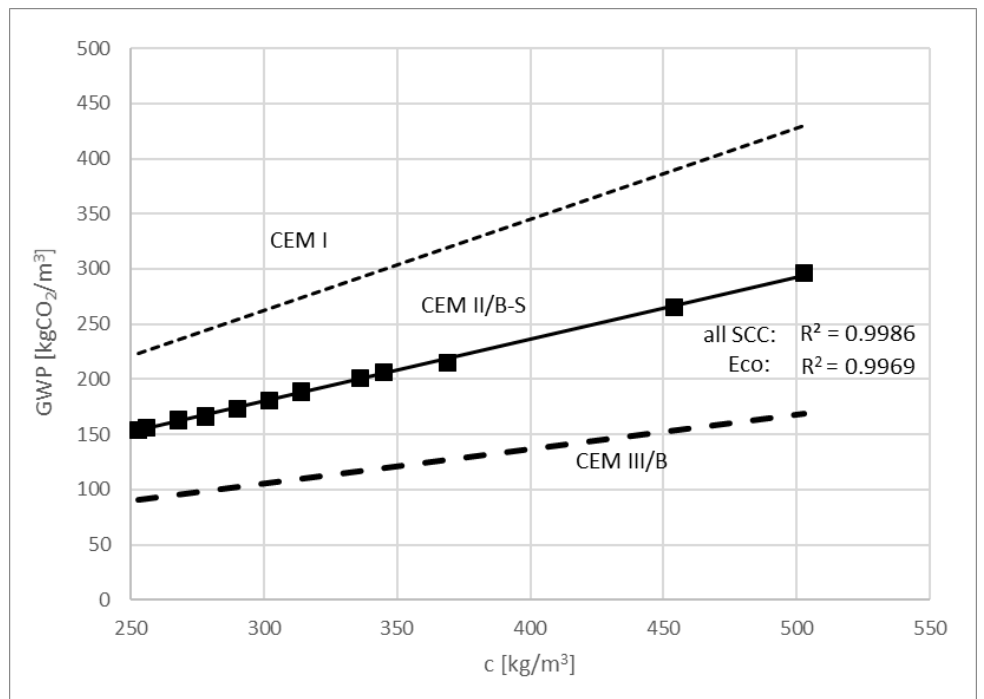

Fig. 3. Global Warming Potential (GWP) as a function of cement content. Solid line with data points - test results. Dashed lines -calculations for hypothetical cement 1:1 replacement.

Consequently, taking into consideration SCC stability requirements, it is clear that the limiting criterion for Eco-SCC should be cement (or cementitious materials) volume (or mass), not binder content, as proposed in [1, 4] (for comparison see Fig. 4). The presented data shows that the bottom limit of Eco-SCC is c.a. $80 \mathrm{dm}^{3} / \mathrm{m}^{3}$ and the top limit should be established at c.a. $100 \mathrm{dm}^{3} / \mathrm{m}^{3}$ (depending on exposure class requirements). Taking all of the above into consideration, the altered definition of Eco-SCC given in the Introduction (maximum $315 \mathrm{~kg} / \mathrm{m}^{3}$ of cementitious materials) is positively verified.

CEMII/B-S produced SCC with GWP of c.a. $165 \mathrm{kgCO}_{2} / \mathrm{m}^{3}$ minimum, only $6 \%$ higher than comparable traditional concrete. For $w / c=0.5$ this difference is almost negligible (3\%). The difference between binder-rich SCC and Eco-SCC in terms of GWP is c.a. 15\%, which is also acceptable. To sum up, the design proposed in [5] (with the alterations presented above) is well-suited for Eco-SCC design. 

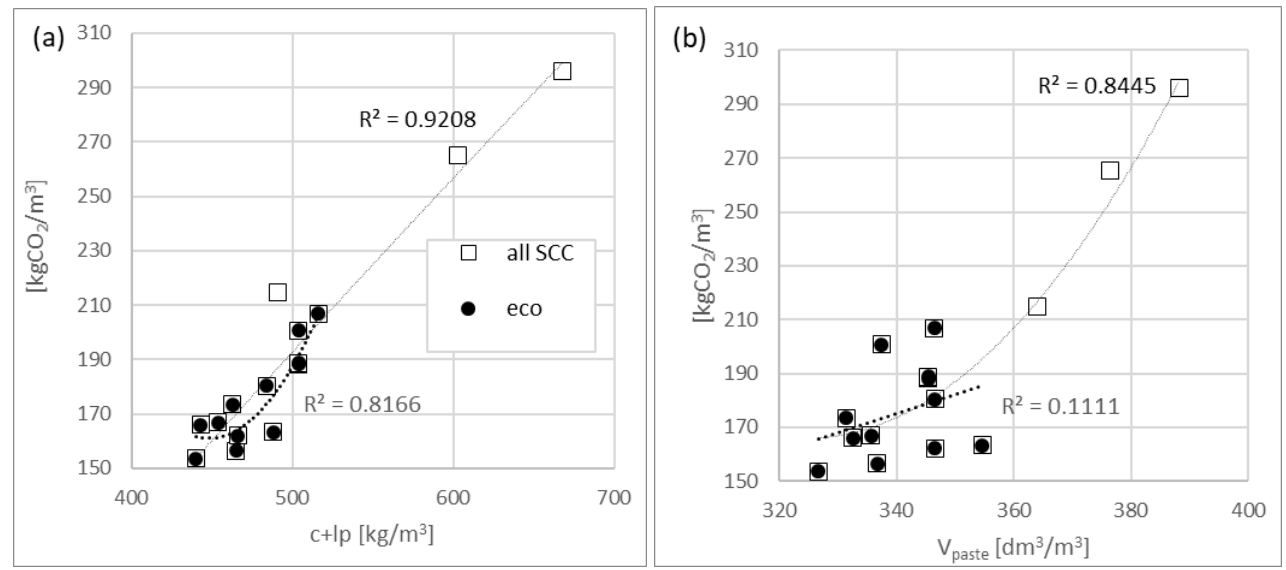

Fig. 4. Global Warming Potential (GWP) as a function of binder (a) and paste content (b).

Table 3 summarises compressive strength results, and strength and exposure classes assessment according to EN-206. The comparison of this data with the matching one concerning mix compositions (Table 1) demonstrates that the given exposure class was obtained using cement content close to the minimum allowed. In contrast, the strength class is typically higher, most probably due to the high strength reserve of the cement used (c.a. $15 \mathrm{MPa}$ measured on standard mortar beams).

Table 3. Test results - Strength and exposure classes.

\begin{tabular}{|c|c|c|c|c|c|c|}
\hline $\begin{array}{l}\text { Mix } \\
\text { no. }\end{array}$ & $\begin{array}{c}f_{\mathrm{cm}} \text { 1day } \\
{[\mathrm{MPa}]}\end{array}$ & $\begin{array}{c}\mathbf{f}_{\mathrm{cm}} 28 \mathrm{day} \\
{[\mathrm{MPa}]}\end{array}$ & $\begin{array}{c}\mathbf{f}_{\mathrm{cm}} 90 \text { day } \\
{[\mathrm{MPa}]}\end{array}$ & $\begin{array}{c}\mathbf{f}_{\text {ck,cube }} \\
{[\mathrm{MPa}]}\end{array}$ & $\begin{array}{c}\text { Strength } \\
\text { class }\end{array}$ & Exposure class \\
\hline $33 \mathrm{R}$ & 15.1 & 85.4 & 93.5 & 77.1 & $\mathrm{C} 60 / 75$ & $\mathrm{XC} 4, \mathrm{XS} 3, \mathrm{XD} 3, \mathrm{XF} 1, \mathrm{XA} 3$ \\
\hline $40 \mathrm{R}$ & 12.8 & 66.2 & 74.6 & 58.9 & $\mathrm{C} 45 / 55$ & $\mathrm{XC} 4, \mathrm{XS} 3, \mathrm{XD} 3, \mathrm{XF} 1, \mathrm{XA} 3$ \\
\hline $50 \mathrm{~S}$ & 11.4 & 51.8 & 58 & 45.2 & $\mathrm{C} 35 / 45$ & $\mathrm{XC} 4, \mathrm{XS} 3, \mathrm{XD} 3, \mathrm{XF} 1, \mathrm{XA} 3$ \\
\hline $50-1$ & - & - & - & - & - & $\mathrm{XC} 4, \mathrm{XS} 1, \mathrm{XD} 2, \mathrm{XF} 1, \mathrm{XA} 2$ \\
\hline $50-2$ & 11.8 & 53.2 & 57.1 & 46.5 & C35/45 & $\mathrm{XC} 4, \mathrm{XS} 1, \mathrm{XD} 2, \mathrm{XF} 1, \mathrm{XA} 2$ \\
\hline $55 \mathrm{R}$ & 9.5 & 52.7 & 64.7 & 46.1 & C35/45 & $\mathrm{XC} 3, \mathrm{XS} 1, \mathrm{XD} 2, \mathrm{XF} 1, \mathrm{XA} 1$ \\
\hline $55-1$ & - & - & - & - & - & $\mathrm{XC} 3, \mathrm{XD} 1, \mathrm{XF} 1, \mathrm{XA} 1$ \\
\hline $55-2$ & 12.1 & 52.5 & 60.5 & 45.9 & $\mathrm{C} 35 / 45$ & $\mathrm{XC} 3, \mathrm{XD} 1, \mathrm{XF} 1, \mathrm{XA} 1$ \\
\hline $60-1$ & - & - & - & - & - & $\mathrm{XC} 2$ \\
\hline $60-2$ & 10.5 & 47.2 & 55.2 & 40.8 & $\mathrm{C} 30 / 37$ & $\mathrm{XC} 2$ \\
\hline $65-1$ & 8.5 & 44.5 & 52 & 38.3 & $\mathrm{C} 30 / 37$ & $\mathrm{XC} 1$ \\
\hline $65-2$ & 9.4 & 46.1 & 55 & 39.8 & $\mathrm{C} 30 / 37$ & $\mathrm{XC} 1$ \\
\hline $70-1$ & - & - & - & - & - & X0 \\
\hline $70-2$ & 7.6 & 39.3 & 48 & 33.3 & $\mathrm{C} 25 / 30$ & $\mathrm{X} 0$ \\
\hline $70-3$ & - & - & - & - & - & X0 \\
\hline $70-4$ & 7 & 39.5 & 49.3 & 33.5 & $\mathrm{C} 25 / 30$ & X0 \\
\hline $70 \mathrm{~S}$ & 7.2 & 38 & 50.2 & 32.1 & $\mathrm{C} 25 / 30$ & X0 \\
\hline
\end{tabular}




\section{Conclusions}

1) There is a possibility to obtain Eco-SCC of excellent fluid properties with only slightly higher GWP (Global Warming Potential) than comparable traditional concretes.

2) It was possible to reach the target specification using the minimum cement content and $w / c$ ratio allowed by EN 206. The only exception is for the concrete strength class, where sometimes results at least one class higher than the minimum were obtained, this is most probably due to the fact that the cement had a very significant strength reserve (15 MPa) in comparison to the minimum standard requirement (acc. to EN 197-1).

3) Aggregate composed using minimum voids in a loose state criterion allowed to obtain a low sand content SCC fulfilling the PL2 requirement. The PL2 passing ability class was predicted owing to Van and Montgomery formula [12] with reasonable accuracy.

4) The presented data show that GWP value in SCC is governed by cement type. Other factors are of lower importance. Two such factors have been recognized. The first is $w / c$ ratio and the second is cement content. This means that cement type and content is an absolutely dominating factor in terms of GWP assessment for SCC containing rounded aggregate and inert additions.

5) Properly chosen inert addition (here: limestone powder) may, in fact, be treated as a powder aggregate (of high GWP in comparison with a natural aggregate). This means that powder SCC always has a higher GWP than traditional concrete of comparable composition, but the difference could be small (here: $3-6 \%$ ).

6) The obtained results lead to the conclusion that the definition of Eco-SCC proposed in literature should be altered, as following: Eco-SCC is an SCC having a cementitious materials content not greater than $315 \mathrm{~kg} / \mathrm{m}^{3}$ or $100 \mathrm{dm}^{3} / \mathrm{m}^{3}$, depending on exposure class.

\section{References}

1. S. Grunewald, G. De Shutter, Concr. Plant. Intern. 10(5), 34-38 (2016)

2. B. Esmaeilkhanian, K.H. Khayat, O.H. Wallevik, Mater, Struct, 50, 124 (2017)

3. M. Urban, Energy Efficient Sustainable Building Materials and Products, 119-136, (ed. I. Hager, Cracow University of Technology Publishing, Kraków, 2017)

4. O.H. Wallevik, F.V. Mueller, B. Hjartarson, S. Kubens, XVII IBAUSIL 1, 1105-1116 (2009)

5. M. Urban, Mater. Struct. 48, 1321-1341(2015)

6. Y. Xie, Y.Liu, G. Long, RILEM PRO054, 189-198 (2007)

7. G. De Shutter, P.J.M. Bartos, P. Domone, J. Gibbs, Self-Compacting Concrete. (Whittless Publ., 2008)

8. M. Urban, Czas. Techn. Politechniki Krakowskiej, seria 'Budownictwo' 14-B/2004, 189-202 (2004) (in Polish)

9. J. Walraven, RILEM PRO033, 15-22 (2003)

10. EFNARC Guidelines for SCC. (EFNARC 2005)

11. ERMCO ready-mix concrete industry statistics, year 2015. (Ed. ERMCO, 2016)

12. B.K. Van, D. Montgomery RILEM PRO007, 373-384(1999)

13. F.V. Mueller, O.H. Wallevik, K.H. Khayat, RILEM PRO100, 25-34 (2016)

14. M. Tokyay, Cement and concrete mineral admixtures (CRC Press, 2016) 